\title{
NLRP3 inflammasome as the potential target mechanism and therapy in recurrent spontaneous abortions
}

\author{
MUDAN LU, FENGYING MA, JIANPING XIAO, LAN YANG, NA LI and DAOZHEN CHEN \\ Central Laboratory, Wuxi Hospital for Maternal and Child Health Care, \\ The Affiliated Hospital of Nanjing Medical University, Wuxi, Jiangsu 214002, P.R. China
}

Received October 21, 2017; Accepted April 13, 2018

DOI: $10.3892 / \mathrm{mmr} .2019 .9829$

\begin{abstract}
Recurrent spontaneous abortions (RSA) are defined as aborting three or more times within 20 gestational weeks with the same sexual partner. The occurrence of RSA exhibits an upward trend in modern society. The NACHT, LRR and PYD domains-containing protein 3 (NLRP3) inflammasome, which is an important component of innate immunity, serves a role in the immune response and in disease occurrence. In the present study, it was demonstrated that the disordered regulation of the NLRP3 inflammasome may induce the occurrence of RSA. The results of the present study demonstrated that caspase-1 activity, interleukin (IL)-1 $\beta$ and IL-18 were upregulated in patients with RSA compared with healthy controls. Further investigation was performed to elucidate the mechanism of activation of the NLRP3 inflammasome in patients with RSA. The inhibition of the NLRP3 inflammasome in a RSA mouse model was able to decrease the rate of abortions. Finally, the present study demonstrated that the activated NLRP3 inflammasome was involved in the pathogenesis of RSA through regulation of the Th17 and regulatory $\mathrm{T}$ cell imbalance. The present study provides a potential future therapeutic target for RSA via the NLRP3 inflammasome.
\end{abstract}

\section{Introduction}

Recurrent spontaneous abortions (RSA) are defined as aborting three or more times within 20 gestational weeks with the same sexual partner. Epidemiological studies have suggested that the occurrence rate of RSA is $1-5 \%$. Multiple factors, including anatomy, genetics, infection, environment, endocrine factors, thrombus and immune factors are

Correspondence to: Dr Mudan Lu or Professor Daozhen Chen, Central Laboratory, Wuxi Hospital for Maternal and Child Health Care, The Affiliated Hospital of Nanjing Medical University, 48 Huaishuxiang, Wuxi, Jiangsu 214002, P.R. China

E-mail: lumudan0527@163.com

E-mail: chendaozhen@163.com

Key words: recurrent spontaneous abortions, NACHT, LRR and PDY domains-containing protein 3 inflammasome involved in the occurrence and development of RSA and some of the possible precipitating factors of RSA remain unknown (1-3). RSA has become a challenge to women of childbearing age and reproductive medicine workers alike. RSA affects the physical and mental health of patients and their families. Therefore, it is important to further investigate the pathogenesis of RSA and seek effective methods to treat RSA, which may provide a novel strategy for the clinical treatment of RSA and be of significance in the field of the RSA research $(4,5)$.

The normal activation of the inflammasome serves an important role in maintaining the stability of the immune system. The inflammasome is gaining increasing amounts of attention in the pathological process of metabolic disorders, autoimmune diseases and types of cancer. The NACHT, LRR and PYD domains-containing protein 3 (NLRP3) inflammasome, which is an important component of innate immunity, serves a role in the immune response and disease occurrence. The abnormal activation and regulation of the NLRP3 inflammasome is associated with a number of autoimmune diseases $(6,7)$. The NLRP3 inflammasome is composed of a variety of protein compounds, which are considered to be innate immune system sensors. The NLRP3 inflammasome recognizes all types of danger signals, induces cell activation and releases inflammatory cytokines causing inflammation (8). The NLRP3 inflammasome hydrolyses the adjacent two pro-caspase-1, then the enzyme initiates the production of the active caspase-1. Active caspase-1 mediates the activation of interleukin (IL)- $1 \beta$ and IL-18 from the precursors of IL- $1 \beta$ and IL- 18 . The activation of the NLRP3 inflammasome also regulates the adaptive immune response. The NLRP3 inflammasome affects the differentiation and function of active helper T cells (9). The NLRP3 inflammasome is closely associated with autoimmune diseases, which indicates that the NLRP3 inflammasome may be associated with the occurrence of recurrent miscarriage (10). In the present study, our aim is to investigate the role and mechanism of NLRP3 inflammasome in RSA. The significance of activation of the NLRP3 inflammasome, caspase-1 and IL-1 $\beta$, IL-18 inflammatory cytokines was studied, which may explain the occurrence of recurrent miscarriage and provide novel ideas for the diagnosis and treatment of inflammation and autoimmune diseases, including RSA. 


\section{Patients and methods}

Patients and controls. The case-control study was approved by the Ethics Committee of Nanjing Medical University (Nanjing, China). A total of 30 patients with RSA and 30 controls from Wuxi Hospital for Maternal and Child Health Care, The Affiliated Hospital of Nanjing Medical University were recruited between July 2014 and June 2017, and all peripheral blood samples were collected from these people subsequent to obtaining written informed consent. The age (mean \pm standard deviation) of women with RSA $(31.2 \pm 3.2$ years) was not significantly different from that of the controls ( $30.5 \pm 3.7$ years). Excluding any definite causes, including abnormalities of the uterus or cervix, chromosomal abnormality, infection, endocrine and metabolic diseases, congenital thrombophilia and autoimmune disease, RSA was diagnosed. Peripheral blood $(20 \mathrm{ml})$ was collected from two different groups at the late follicular phase (days 9-12) of the menstrual cycle. A total of 30 fertile women who had at least one successful pregnancy and no previous abortions, with regular menstrual cycles, were used as the control group. None of the women in the present study were taking oral contraceptives.

Experimental animals of RSA. A total of 3010 -week-old mice [female CBA/J $\left(\mathrm{h}-2^{\mathrm{k}}\right)$ mice, male DBA/2J (h-2 $\left.{ }^{\mathrm{d}}\right)$ and male $\mathrm{Balb} / \mathrm{c}\left(\mathrm{h}-\mathrm{2}^{\mathrm{d}}\right.$ ); 10 mice in each group] weighing 20-30 g were obtained from the Beijing Institute of Laboratory Animals of the Chinese Academy of Medical Sciences (Beijing, China). The mice were housed at $24^{\circ} \mathrm{C}$ with 12 -h light/dark cycle and free access to food and water with breeding conditions complying with special pathogen free standards. The experimental protocols for animals were approved by the Ethics Committee of Nanjing Medical University. Male Balb/c or DBA/2J mice were bred with female CBA/J mice and the vaginal plugs in individual mated female mice were examined daily to determine potential pregnancy. CBA/J mice mated with Balb/c mice were used as the normal pregnancy group. $\mathrm{CBA} / \mathrm{J}$ mice mated with $\mathrm{DBA} / 2 \mathrm{~J}$ were considered as the spontaneous abortion group. Each group had 10 mice.

ELISA. To assess the levels of caspase-1 activity, and IL-1 $\beta$ and IL-18 expression in the peripheral blood monocytes (PBMC) of patients with RSA and spleen tissues of model mice, ELISA analysis was performed using respective ELISA kits (eBioscience; Thermo Fisher Scientific, Inc., Waltham, MA, USA) for IL-1 $\beta$ (KHC0019) and IL-18, (MAN0014360) and Beyotime Institute of Biotechnology, Haimen, China for caspase-1 activity (P70380) according to the manufacturer's protocols.

Reverse transcription-quantitative polymerase chain reaction (RT-qPCR) analysis. Total RNA was isolated from the PBMCs of patients or the spleen tissue of mice with TRIzol reagent (Invitrogen; Thermo Fisher Scientific, Inc.) and was reverse transcribed at $50^{\circ} \mathrm{C}$ for 60 min using a PrimeScript RT reagent kit (Takara Bio, Inc., Otsu, Japan), according to the manufacturer's protocol. Subsequently, cDNA was subjected to qPCR using a Lightcycler480 and SYBR-Green system (Roche Diagnostics, Basel, Switzerland) following the manufacturer's protocol. The primer sequences used in the present study were as follows: i) forward, NLRP3: 5'-CGAGACCTCTGGGAA AAAGCT-3' and reverse, 5'-GCATACCATAGAGGAATG TGATGTAC-3'; ii) GAPDH forward, 5'-CTCTGGAAAGCT GTGGCGTGATG-3' and reverse, 5'-ATGCCAGTGAGCTTC CCGTTCAG-3'. GAPDH was used as a housekeeping gene for normalization. The cycling parameters were as follows: Denaturation at $95^{\circ} \mathrm{C}$ for $10 \mathrm{~min}$, amplification at $95^{\circ} \mathrm{C}$ for $15 \mathrm{sec}, 58^{\circ} \mathrm{C}$ for $1 \mathrm{~min}$ and $72^{\circ} \mathrm{C}$ for $1 \mathrm{~min}$ for 40 cycles. NLRP3 expression was calculated following normalization to GAPDH expression levels by the comparative $2^{-\Delta \Delta \mathrm{Cq}}$ quantification cycle method (11).

Inhibition of caspase-1. In the present study, a highly specific, cell-permeable and competitive inhibitor of caspase-1 was used as previously described $(12,13)$. Briefly, the mated model mice received the first intraperitoneal injection of $0.5 \mathrm{mg}$ Ac-Tyr-Val-Ala-Asp-2,6-dimethylbenzoyloxymethyl ketone (Ac-YVAD-CHO; Bachem AG, Bubendorf, Switzerland) dissolved in $0.1 \mathrm{ml}$ sterile phosphate-buffered saline $(\mathrm{pH}$ 7.4) on day 0 . This was repeated every three days. Mice receiving treatment with PBS were used as a control.

Detection of Th17 [cluster of differentiation $(C D) 4^{+} I L-17 A^{+}$] and regulatory $T$ cells [Treg; $\mathrm{CD}^{+} \mathrm{CD}^{2} 5^{+}$forkhead box protein $\left.\mathrm{P} 3\left(\mathrm{FOXP}^{+}\right)\right]$in RSA and controls by flow cytometry. For analysis of Th17 cells, PBMCs $\left(2 \times 10^{6}\right.$ cells $\left./ \mathrm{ml}\right)$ were suspended in culture medium including RPMI-1640 (Invitrogen; Thermo Fisher Scientific, Inc.) with L-glutamine, penicillin $(100 \mathrm{U} / \mathrm{ml})$, streptomycin $(10 \mathrm{mg} / \mathrm{ml})$ and $10 \%$ fetal bovine serum (Invitrogen; Thermo Fisher Scientific, Inc.). Cells were stained for the surface marker CD4 by incubation with fluorescein isothiocyanate-conjugated anti-human CD4 (1:30; cat. no. 11-0041-82; eBioscience; Thermo Fisher Scientific, Inc.) at $4^{\circ} \mathrm{C}$ for $30 \mathrm{~min}$. Subsequently, the cells were fixed in $4 \%$ paraformaldehyde at $4^{\circ} \mathrm{C}$ for $30 \mathrm{~min}$ and then stained with phycoerythrin (PE)-conjugated anti-human IL-17A (1:50; cat. no. 25-7177-82; eBioscience; Thermo Fisher Scientific, Inc.) for Th17 cell detection, following fixation and permeabilization according to the manufacturer's protocol, by flow cytometric analysis as in a previous study (14). Similarly, for Treg cell staining, cells were incubated with PerCP anti-human CD4 (1:40; cat. no. 46-0047-42; eBioscience; Thermo Fisher Scientific, Inc.) and CD25 (1:40; cat. no. 11-0257-42; eBioscience; Thermo Fisher Scientific, Inc.) at $4^{\circ} \mathrm{C}$ for $30 \mathrm{~min}$. Following surface staining, the cells were fixed in $4 \%$ paraformaldehyde for $30 \mathrm{~min}$ at $4^{\circ} \mathrm{C}$ and intracellularly stained with PE-anti-human FOXP3 (1:60; cat. no. 12-4777-42; eBioscience; Thermo Fisher Scientific, Inc.). All data were analyzed by flow cytometry and analyzed by FlowJo software version 10 (FlowJo LLC, Ashland, OR, USA), as described in a previous study $(14,15)$.

Statistical analysis. Data are presented as the mean \pm standard deviation from three independent experiments. Comparisons between patients with RSA and controls were analyzed via the Student's t test. Correlation analysis was performed via the Pearson correlation test. All analyses were performed using GraphPad Prism 5 (GraphPad Software, Inc., La Jolla, CA, USA). $\mathrm{P}<0.05$ was considered to indicate a statistically significant difference. 

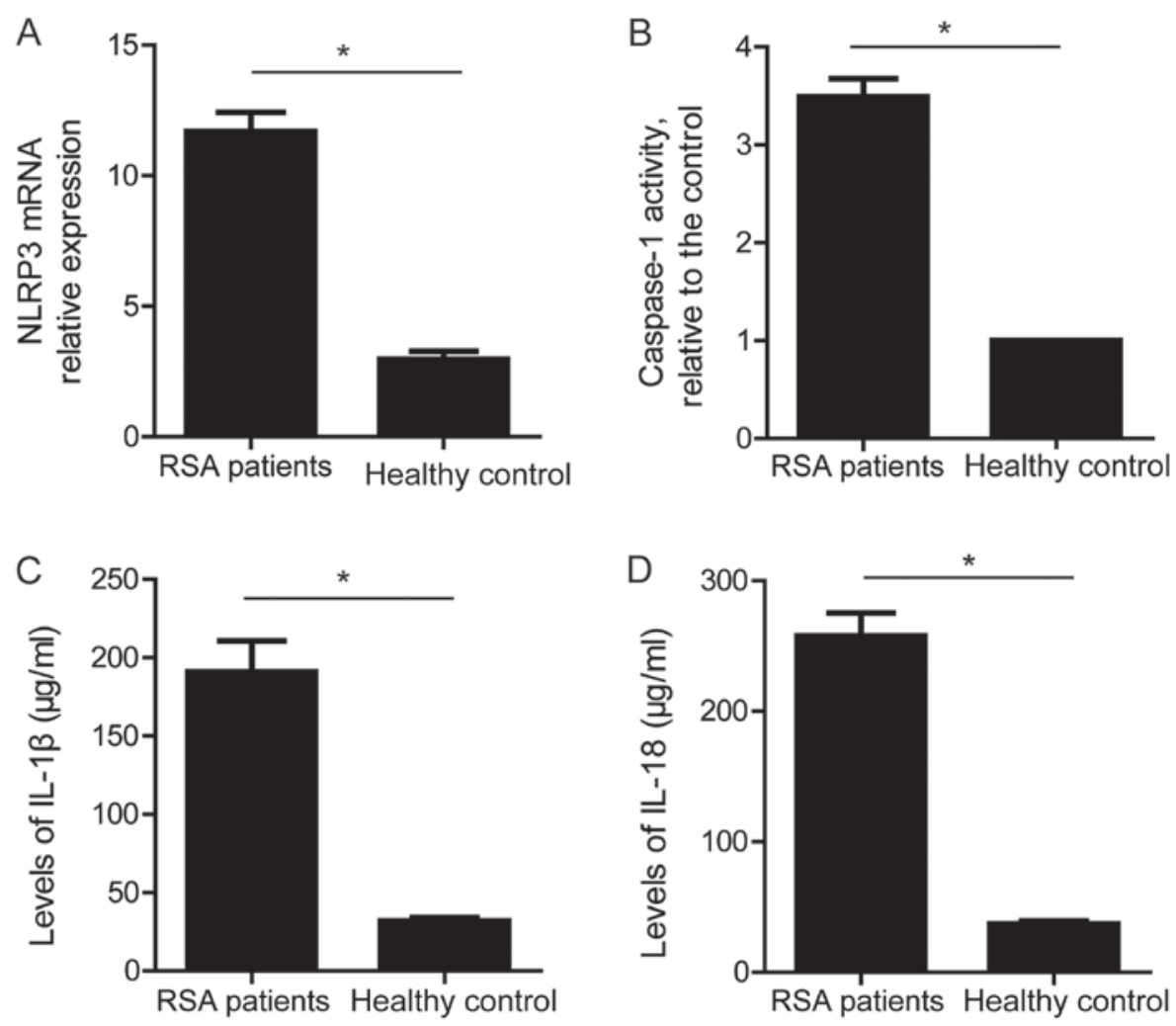

Figure 1. Expression of the NLRP3 inflammasome in patients with RSA and controls. (A) The NLRP3 mRNA expression levels analyzed by reverse transcription-quantitative polymerase chain reaction analysis in patients with RSA and controls. (B) The caspase-1 activity analyzed by ELISA in patients with RSA and controls. (C) The IL-1 $\beta$ expression levels analyzed by ELISA in patients with RSA and controls. (D) The IL-18 expression levels analyzed by ELISA in patients with RSA and controls. "P<0.05. RSA, recurrent spontaneous abortions; IL, interleukin; NLRP3, NACHT, LRR and PYD domains-containing protein 3.

\section{Results}

Expression of the NLRP3 inflammasome in RSA patients. Embryos carry one-half of the tissue antigens derived from the parents, therefore the embryo is half allogeneic grafts to the mother. However, throughout the pregnancy, the embryo survives attacks from the immune system of the mother, which is attributed to tolerance towards the embryo by the mother's immune system (16-18). Once the immune tolerance is overcome, however, it will lead to abortion $(19,20)$. Therefore, how the embryo escapes from attack by the immune system in pregnant women is complex.

Inflammasomes have been widely implicated in the development and progression of various chronic diseases (21-23). The NOD-like receptor (NLR) family was the first researched inflammasome. Once the NLR family is activated, NLRP3 recruits the adapter apoptosis-related speck-like protein containing a caspase recruitment domain, which in turn recruits procaspase-1.Procaspase-1 autocatalyzes its own cleavage and activation, resulting in maturation of the precursor forms of IL-1 $\beta$ and IL-18 into active proinflammatory cytokines and the initiation of pyroptotic cell death (24).

Abortion is closely associated with the immune response in pregnant women. To investigate whether the NLRP3 inflammasome is involved in RSA, the expression of NLRP3 mRNA expression levels in PBMCs of patients with RSA and controls was analyzed. It was demonstrated that the NLRP3 mRNA expression levels were significantly increased in RSA patients compared with the healthy controls $(\mathrm{P}<0.05$; Fig. 1A). The same results were obtained in the decidual tissue (data not shown). It was then demonstrated that caspase-1 activity was significantly upregulated in patients with RSA compared with the healthy controls $(\mathrm{P}<0.05$; Fig. 1B). Furthermore, expression levels of IL-1 $\beta$ (Fig. 1C) and IL-18 (Fig. 1D) were significantly increased in the patients with RSA $(\mathrm{P}<0.05)$. These results suggested that the NLRP3 inflammasome was activated in patients with RSA. Further studies were performed to investigate the mechanism of activation of the NLRP3 inflammasome in RSA patients.

Expression of the NLRP3 inflammasome in the RSA mouse model. CBA/J mice mated with Balb/c mice were used as the control group with normal pregnancy. CBA/J mice mated with DBA/2J served as the spontaneous abortion group. The NLRP3 mRNA expression levels in the splenic tissue in the RSA and control mouse models were analyzed. The results demonstrated that the NLRP3 mRNA level was also significantly upregulated in the RSA model ( $\mathrm{P}<0.05$; Fig. 2A). Following this, the caspase-1 activity and expression levels of IL-1 $\beta$ and IL-18 in the RSA and control mice model were examined. The results demonstrated that the caspase- 1 activity was significantly increased $(\mathrm{P}<0.05$; Fig. $2 \mathrm{~B})$ as was IL-1 $\beta$ $(\mathrm{P}<0.05$; Fig. 2C) and IL-18 expression ( $\mathrm{P}<0.05$; Fig. 2D). These results suggested that the NLRP3 inflammasome was activated in the RSA mouse model.

Inhibition of NLRP3 inflammasome in the RSA mouse model could rescue the abortion-prone mice. The above results suggested that the NLRP3 inflammasome was activated in 

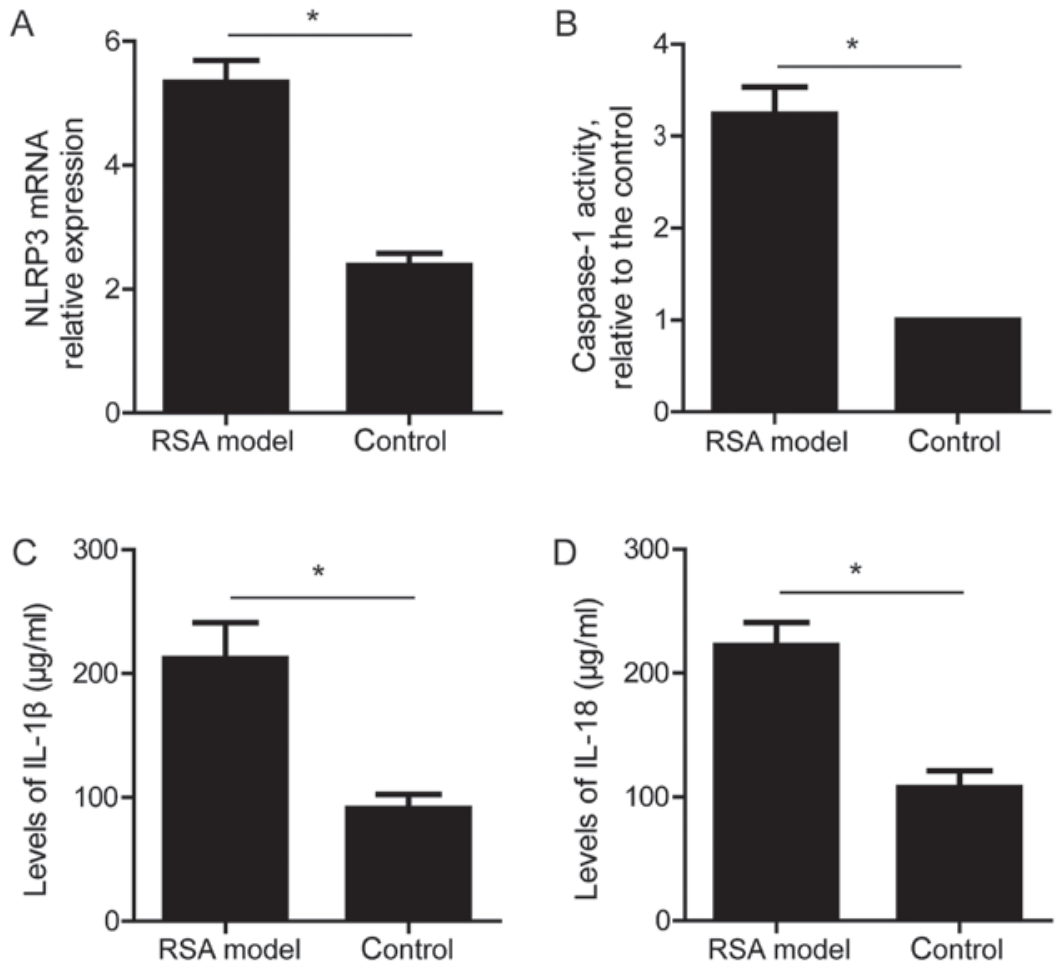

Figure 2. Expression of the NLRP3 inflammasome in the RSA mouse model.(A) The NLRP3 mRNA expression levels analyzed by reverse transcription-quantitative polymerase chain reaction analysis in the RSA mouse model and controls. (B) The caspase-1 activity analyzed by ELISA in the RSA mouse model and controls. (C) The IL-1 $\beta$ expression levels analyzed by ELISA in the RSA mouse model and controls. (D) The IL-18 expression levels analyzed by ELISA in the RSA mouse model and controls. "P<0.05. RSA, recurrent spontaneous abortions; IL, interleukin; NLRP3, NACHT, LRR and PYD domains-containing protein 3.
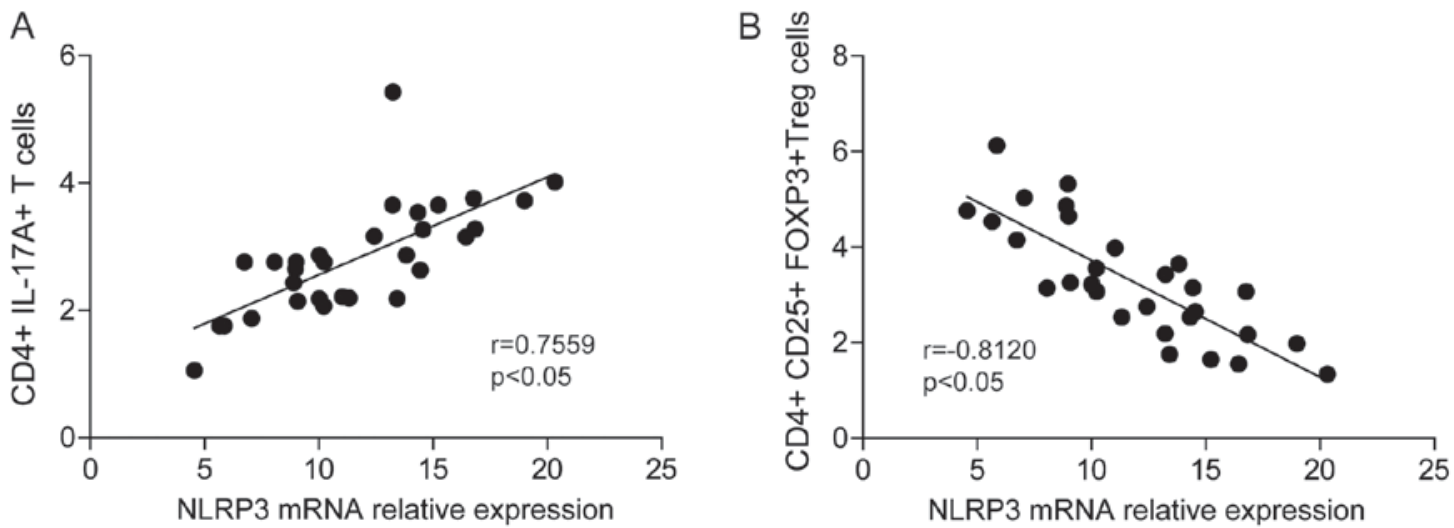

Figure 3. Investigation of the involvement of Th17 and Tregs in the inflammasome in patients with RSA. (A) The correlation of NLRP3 expression levels and Treg T cells in patients with RSA. (B) The correlation of NLRP3 expression levels and Th17 T cells in patients with RSA. Treg, regulatory T cells; RSA, recurrent spontaneous abortions; IL, interleukin; CD, cluster of differentiation; FOXP3, forkhead box protein P3; NLRP3, NACHT, LRR and PDY domains-containing protein 3 .

the patients with RSA and the mouse model. The caspase-1 inhibitor YVAD was used to pretreat the abortion-prone mice. On day 14 of pregnancy, the abortion-prone mice treated with YVAD had a low embryo resorption rate compared with the untreated abortion-prone mice. These results proved that the inhibition of the NLRP3 inflammasome in the RSA mouse model was able to protect the abortion-prone mice (Table I).

Activated NLRP3 inflammasome is involved in the pathogenesis of RSA through regulation of the Th17 and Treg imbalance. Th17 cells serve an important role in the inflammatory reaction through the release of the pro-inflammatory cytokine IL-17. Therefore, Th17 cells may be proinflammatory factors in embryonic immune rejection. However, Treg cells (primarily $\mathrm{CD} 4^{+} \mathrm{CD} 25^{+}$Treg) induce immune tolerance, which is a unique immune regulatory function in the $\mathrm{T}$ cell subgroup (25). Treg and Th17 cells are important in immune rejection; a number of studies have demonstrated that an imbalance of Th17 and Tregs may lead to the occurrence of RSA $(23,25)$. Whether the NLRP3 inflammasome is associated with Treg and Th17 cells was investigated in the present study. The correlation between NLRP3 and IL-17, and NLRP3 and CD4 ${ }^{+}$CD $25^{+}$Treg cells was analyzed. The results demonstrated that the NLRP3 expression was positively correlated with the $\mathrm{CD} 4^{+} \mathrm{IL}-17 \mathrm{~A}^{+}$levels $(\mathrm{r}=0.76$; Fig. 3A), while NLRP3 expression was negatively correlated with $\mathrm{CD} 4{ }^{+} \mathrm{CD} 25^{+}$Treg cells (r=-0.81; Fig. 3B). Similar results 
Table I. Treatment with YVAD was able to protect the abortion-prone mice in the RSA mouse model.

\begin{tabular}{lcccc}
\hline & No. of mice & Surviving fetuses & Resorbed fetuses & Resorption rate, \% \\
\hline Control & 10 & 69 & 12 & 17.39 \\
RSA & 10 & 51 & 22 & 43.14 \\
Vehicle & 10 & 47 & 20 & 42.55 \\
YVAD & 10 & 45 & 12 & 26.67
\end{tabular}

RSA, recurrent spontaneous abortions.
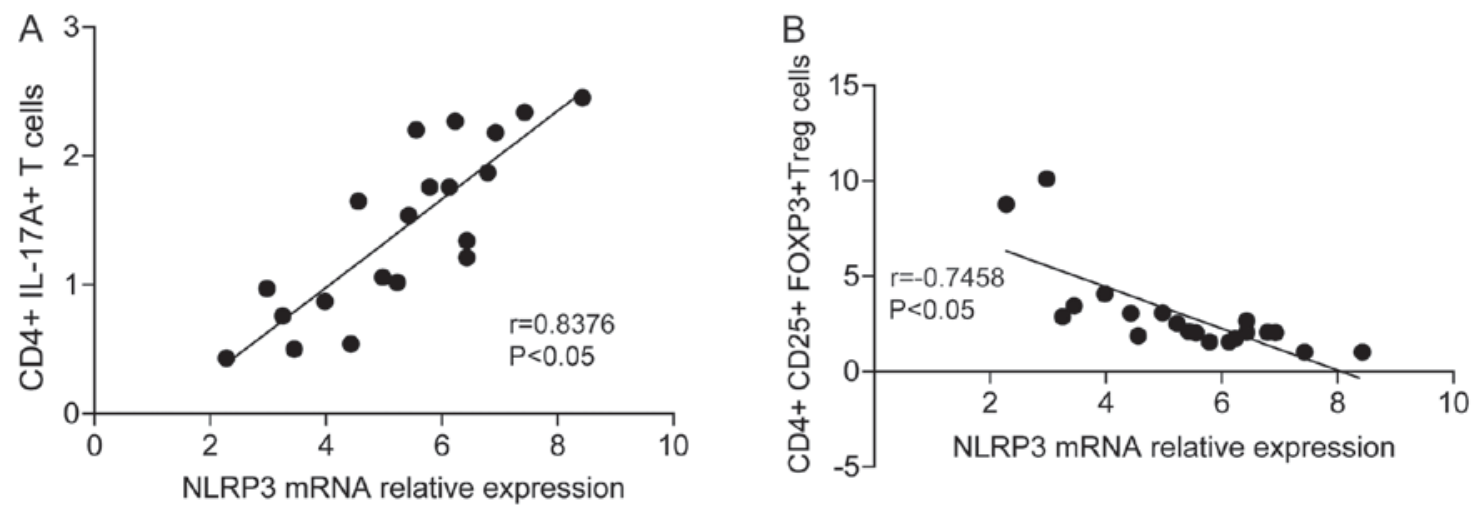

Figure 4. Investigation of the association of Th17 and Tregs with the inflammasome in the RSA mouse model. (A) The correlation of NLRP3 expression levels and Treg T cells in the RSA mouse model. (B) The correlation of NLRP3 expression levels and Th17 cells in the RSA mouse model. RSA, recurrent spontaneous abortions; Treg, regulatory T cells; IL, interleukin; CD, cluster of differentiation; FOXP3, forkhead box protein P3; NLRP3, NACHT, LRR and PDY domains-containing protein 3.

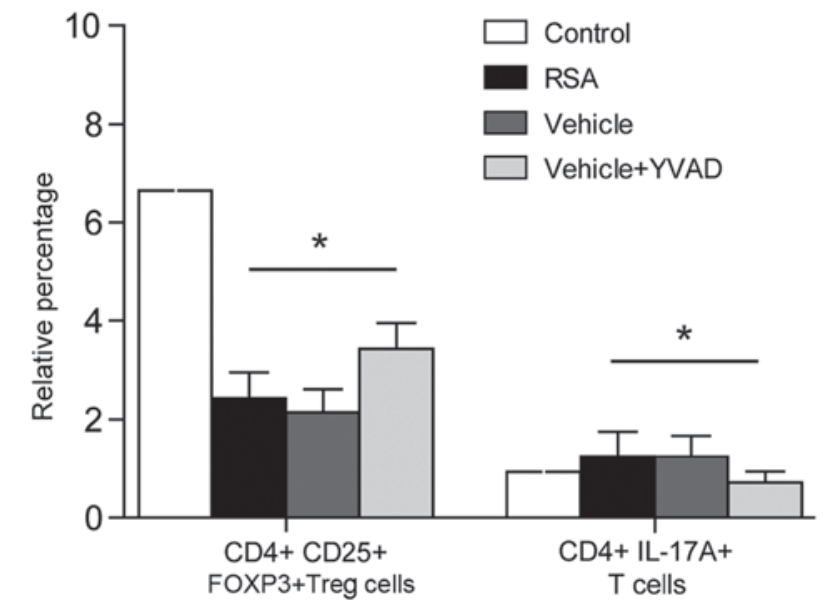

Figure 5. Detection of $\mathrm{CD} 4^{+} \mathrm{IL}-17 \mathrm{~A}^{+}$and $\mathrm{CD} 4^{+} \mathrm{CD} 25^{+}$Treg levels in RSA mice treated with the YVAD inhibitor. ${ }^{*} \mathrm{P}<0.05$. $\mathrm{CD}$, cluster of differentiation; RSA, recurrent spontaneous abortions; Treg, regulatory T cells IL, interleukin; $\mathrm{CD}$, cluster of differentiation; FOXP3, forkhead box protein $\mathrm{P}$; NLRP3, NACHT, LRR and PDY domains-containing protein 3.

were observed the RSA mouse model (Fig. 4). The CD4+ IL-17A ${ }^{+}$ and $\mathrm{CD} 4{ }^{+} \mathrm{CD} 25^{+}$Treg levels in the RSA mice were investigated with the caspase-1 inhibitor YVAD. The results demonstrated that treatment with YVAD increased the CD4 ${ }^{+} \mathrm{CD} 25^{+}$Treg levels while the $\mathrm{CD}^{+}{ }^{+} \mathrm{IL}-17 \mathrm{~A}^{+}$levels were downregulated (Fig. 5). These results suggested that the activated NLRP3 inflammasome was involved in the pathogenesis of RSA by regulating the Th17 and Treg imbalance.

\section{Discussion}

RSA occurs in $1-5 \%$ of women during their reproductive years (26). The exact mechanism of RSA is remains unclear. Certain studies have suggested that the onset of RSA has been associated with maternal immune system attack on the fetus by allo-rejection (27-29). A previous study observed that Th2-anti-inflammatory predominance facilitated the survival of the fetus in the maternal uterus (30). However, a previous study demonstrated that the lack of Th2 cytokine secretion of genetically deficient mice did not always cause abortion, suggesting that multiple factors were involved in the pathogenesis of RSA (31). Previous studies have demonstrated that Treg (31) and Th17 (32) are involved in abortion. The imbalance of Treg and Th17 leads to abortion through the secretion of inflammatory cytokines. The focus of the present study was the mechanism underlying the imbalance of Treg and Th17 cells. A previous study demonstrated that the NLRP3 inflammasome serves an important role in inflammatory and autoimmune diseases (33). In the present study, it was demonstrated that the NLRP3 inflammasome was activated in patients with RSA and the mouse model. Further experiments demonstrated that the inhibition of the NLRP3 inflammasome in the RSA mouse model was able to rescue abortion-prone mice. Finally, the results demonstrated that the activated NLRP3 inflammasome is involved in the pathogenesis of RSA by regulating the Th17 and Treg balance disturbance.

Once danger signals meet the immune system, the NLRP3 inflammasome is activated. Following this, the NLRP3 
inflammasome increases the secretion of active caspase-1, and IL-1 $\beta$ and IL-18, which are inflammatory cytokines (34). In the present study it was demonstrated that the mRNA expression levels of NLRP3 were increased in addition to the active caspase-1, IL-1 $\beta$ and IL-18 in the women with RSA compared with the controls. These results suggested that the NLRP3 inflammasome may be involved in abortion.

The cytokines induced by the NLRP3 inflammasome have individual characteristics. IL-1, which is considered to be a powerful inflammatory mediator, may induce acute systemic or local inflammation and contributes to a number of chronic diseases. IL-1 is associated with a number of autoimmune diseases, including atherosclerosis, osteoarthritis, metabolic syndrome and type 2 diabetes (35). The secretion of IL-1 $\beta$ consists of a number of stages. First, an activated antigen triggers IL-1 $\beta$ expression in inflammatory cells. Second, the IL-1 $\beta$ precursor protein, which has no biological activity in the cytosol, is translated from the IL-1 $\beta$ mRNA. Finally, the cell secretes activated IL-1 $\beta$. The inflammasome, including activated caspase-1 and pro-IL-18, was discovered by Cerretti et al (36), Thornberry et al (37), Miura et al (38) and Martinon et al (39).

Although inflammasomes exist in different forms, the constituent parts of the inflammasomes are similar, including the NLR gene family, adaptor proteins and procaspase-1 molecules (40). The NLRP3 inflammasome is the most important inflammasome in sterile inflammation. Diverse stimulation, including pore-forming toxins, bacteria, viruses and endogenous molecules, may activate the NLRP3 inflammasome $(41,42)$.

Pathogen-associated and damage-associated molecular patterns may activate the NLRP3 inflammasome. Following this, the NLRP3 inflammasome induces the secretion of important pro-inflammatory cytokines, including IL-1 $\beta$ and IL-18 $(43,44)$. The NLRP3 inflammasome is involved in a variety of biological activities, including inflammation and tissue repair. Recent studies demonstrated that numerous sensor proteins of endogenous and exogenous origins have been involved in NLRP3 inflammasome activation. In metabolic syndrome and inflammatory bowel disease (45), NLRP3 inflammasome activation exerts important roles. Furthermore, mutations in components of inflammasome complexes have been associated with a propensity for the development of a number of immune-mediated diseases in humans (46).

A number of studies have suggested that Treg and Th17 cells serve important roles in the pathogenesis of RSA $(6,7,25,47-49)$. Treg cells may induce tolerance and maintain tolerance to alloantigens. Th17 cells produce the signature cytokine IL-17 to mediate inflammation, autoimmunity and immunological rejection of foreign tissue $(50,51)$. The results of the present study demonstrated that the activated NLRP3 inflammasome is involved in the pathogenesis of RSA by regulating Th17 and Treg balance disturbance.

In conclusion, the authors of the present study suggested that the NLRP3 inflammasome was activated in patients with RSA by regulating Th17 and Treg balance disturbance. The NLRP3 inflammasome may be used as a therapeutic target for RSA in the future.

\section{Acknowledgements}

Not applicable.

\section{Funding}

The present study was supported by: The National Natural Scientific Foundation of China (grant nos. 30872999 and 81372480); a grant from Revitalize and Defend the Key Talent's Subsidy Project in Science and Education of Department of Public Health of Jiangsu Province (grant no. RC2011033); a grant for the Key Talents of Young Medical Science in the Jiangsu Province (grant no. QNRC2016169); a grant for Jiangsu Natural Science Youth Fund (grant no. BK20170209); The China Postdoctoral Research Foundation (grant no. 180942); The Jiangsu Province Postdoctoral Research Foundation (grant no. 1701012A); The Wuxi Science and Technological Developmental Project (grant no. CSE31N1427); and The Project of Wuxi Health and Family Planning Commission (grant no. YGZXM1401).

\section{Availability of data and materials}

All data generated or analyzed during this study are included in this published article.

\section{Authors' contributions}

The experiments were conceived and designed by ML and DC, and the experiments were performed by LY and NL. FM and JX contributed reagents, materials and analytical tools, and analyzed the data. ML and DC wrote the paper.

\section{Ethics approval and consent to participate}

The case-control study was approved by the Ethics Committee of Nanjing Medical University. Informed consent was obtained from all participants. The experimental protocols for animals were approved by the Ethics Committee of Nanjing Medical University.

\section{Patients consent for publication}

Written informed consent was obtained from all participants.

\section{Competing interests}

The authors declare that they have no competing interests.

\section{References}

1. Larsen EC, Christiansen OB, Kolte AM and Macklon N: New insights into mechanisms behind miscarriage. BMC Med 11: 154, 2013.

2. Kwak-Kim J, Agcaoili MS, Aleta L, Liao A, Ota K, Dambaeva S, Beaman K, Kim JW and Gilman-Sachs A: Management of women with recurrent pregnancy losses and antiphospholipid antibody syndrome. Am J Reprod Immunol 69: 596-607, 2013.

3. Shetty S, Patil R and Ghosh K: Role of microparticles in recurrent miscarriages and other adverse pregnancies: A review. Eur J Obstet Gynecol Reprod Biol 169: 123-129, 2013.

4. Hovdenak $\mathrm{N}$ and Haram K: Influence of mineral and vitamin supplements on pregnancy outcome. Eur J Obstet Gynecol Reprod Biol 164: 127-132, 2012.

5. Martínez-Zamora MÁ, Cervera R and Balasch J: Recurrent miscarriage, antiphospholipid antibodies and the risk of thromboembolic disease. Clin Rev Allergy Immunol 43: 265-274, 2012. 
6. Saini V, Arora S, Yadav A and Bhattacharjee J: Cytokines in recurrent pregnancy loss. Clin Chim Acta 412: 702-708, 2011.

7. van Mourik MS, Macklon NS and Heijnen CJ: Embryonic implantation: Cytokines, adhesion molecules, and immune cells in establishing an implantation environment. J Leukoc Biol 85: 4-19, 2009.

8. Piccinni MP, Scaletti C, Maggi E and Romagnani S: Role of hormone-controlled Th1- and Th2-type cytokines in successful pregnancy. J Neuroimmunol 109: 30-33, 2000.

9. Chaouat G, Lédée-Bataille N, Zourbas S, Ostojic S, Dubanchet S Martal J and Frydman R: Cytokines, implantation and early abortion: Re-examining the Th1/Th2 paradigm leads to question the single pathway, single therapy concept. Am J Reprod Immunol 50: 177-186, 2003.

10. D'Ippolito S, Tersigni C, Marana R, Di Nicuolo F, Gaglione R, Rossi ED, Castellani R, Scambia G and Di Simone N: Inflammosome in the human endometrium: Further step in the evaluation of the 'maternal side'. Fertil Steril 105: 111-118.e1-e4, 2016.

11. Livak KJ and Schmittgen TD: Analysis of relative gene expression data using real-time PCR and the 2(-Delta Delta C(T)) method. Methods 25: 402-408, 2001.

12. Paszkowski AS, Rau B, Mayer JM, Möller P and Beger HG: Therapeutic application of caspase 1/interleukin-lbeta-converting enzyme inhibitor decreases the death rate in severe acute experimental pancreatitis. Ann Surg 235: 68-76, 2002.

13. Westermann D, Van Linthout S, Dhayat S, Dhayat N, Escher F, Bücker-GärtnerC, Spillmann F, Noutsias M, Riad A, Schultheiss HP and Tschöpe C: Cardioprotective and anti-inflammatory effects of interleukin converting enzyme inhibition in experimental diabetic cardiomyopathy. Diabetes 56: 1834-1841, 2007.

14. Sereshki N, Gharagozloo M, Ostadi V, Ghahiri A, Roghaei MA Mehrabian F, Andalib AA, Hassanzadeh A, Hosseini H and Rezaei A: Variations in T-helper 17 and regulatory $\mathrm{T}$ cells during the menstrual cycle in peripheral blood of women with recurrent spontaneous abortion. Int J Fertil Steril 8: 59-66, 2014.

15. Wang WJ, Hao CF, Yi-Lin, Yin GJ, Bao SH, Qiu LH and Lin QD Increased prevalence of T helper 17 (Th17) cells in peripheral blood and decidua in unexplained recurrent spontaneous abortion patients. J Reprod Immunol 84: 164-170, 2010.

16. Potdar N, Gelbaya T and Nardo LG: Endometrial injury to overcome recurrent embryo implantation failure: A systematic review and meta-analysis. Reprod Biomed Online 25: 561-571, 2012.

17. Denny KJ, Woodruff TM, Taylor SM and Callaway LK: Complement in pregnancy: A delicate balance. Am J Reprod Immunol 69: 3-11, 2013.

18. Kokcu A, Yavuz E, Celik H and Bildircin D: A panoramic view to relationships between reproductive failure and immunological factors. Arch Gynecol Obstet 286: 1283-1289, 2012.

19. Nakashima A, Shima T, Inada K, Ito M and Saito S: The balance of the immune system between T cells and NK cells in miscarriage. Am J Reprod Immunol 67: 304-310, 2012.

20. Jin LP, Fan DX and Li DJ: Regulation of costimulatory signal in maternal-fetal immune tolerance. Am J Reprod Immunol 66 : 76-83, 2011

21. Rock KL, Kataoka H and Lai JJ: Uric acid as a danger signal in gout and its comorbidities. Nat Rev Rheumatol 9: 13-23, 2013.

22. Grebe A and Latz E: Cholesterol crystals and inflammation. Curr Rheum Rep 15: 313, 2013

23. Jourdan T, Godlewski G, Cinar R, Bertola A, Szanda G, Liu J, Tam J, Han T, Mukhopadhyay B, Skarulis MC, et al: Activation of the Nlrp3 inflammasome in infiltrating macrophages by endocannabinoids mediates beta cell loss in type 2 diabetes. Nat Med 19 $1132-1140,2013$

24. Kirwan AM, Lenighan YM, O'Reilly ME, McGillicuddy FC and Roche HM: Nutritional modulation of metabolic inflammation. Biochem Soc Trans 45: 979-985, 2017.

25. Peck A and Mellins ED: Plasticity of T-cell phenotype and function: The T helper type 17 example. Immunology 129: 147-153, 2010.

26. Lin QD and Qiu LH: Pathogenesis, diagnosis, and treatment of recurrent spontaneous abortion with immune type. Front Med China 4: 275-279, 2010.

27. Druckmann R and Druckmann MA: Progesterone and the immunology of pregnancy. J Steroid Biochem Mol Biol 97: 389-396, 2005

28. Cohen RA, Check JH and Dougherty MP: Evidence that exposure to progesterone alone is a sufficient stimulus to cause a precipitous rise in the immunomodulatory protein the progesterone induced blocking factor (PIBF). J Assist Reprod Genet 33: $221-229,2016$
29. Jin LP, Fan DX, Zhang T, Guo PF and Li DJ: The costimulatory signal upregulation is associated with Th1 bias at the maternal-fetal interface in human miscarriage. Am J Reprod Immunol 66: 270-278, 2011.

30. Raghupathy R, Makhseed M, Azizieh F, Hassan N, Al-Azemi M and Al-Shamali E: Maternal Th1- and Th2-type reactivity to placental antigens in normal human pregnancy and unexplained recurrent spontaneous abortions. Cell Immunol 196: 122-130, 1999.

31. Zenclussen AC: Regulatory T cells in pregnancy. Springer Semin Immunopathol 28: 31-39, 2006.

32. Wang WJ, Liu FJ, Qu HM, Hao CF, Qu QL, Xiong-Wang, Bao HC and Wang XR: Regulation of the expression of Th17 cells and regulatory T cells by IL-27 in patients with unexplained early recurrent miscarriage. J Reprod Immunol 99: 39-45, 2013.

33. Mangan MS and Latz E: TAK1ng control: TAK1 restrains NLRP3 activation. J Exp Med 215: 1007-1008, 2018.

34. Poudel B and Gurung P: An update on cell intrinsic negative regulators of the NLRP3 inflammasome. J Leukoc Biol: Jan 26 , 2018 (Epub ahead of print).

35. Dinarello CA: A clinical perspective of IL-1 $\beta$ as the gatekeeper of inflammation. Eur J Immunol 41: 1203-1217, 2011.

36. Cerretti DP, Kozlosky CJ, Mosley B, Nelson N, Van Ness K, Greenstreet TA, March CJ, Kronheim SR, Druck T, Cannizzaro LA, et al: Molecular cloning of the interleukin-1beta converting enzyme. Science 256: 97-100, 1992.

37. Thornberry NA, Bull HG, Calaycay JR, Chapman KT, Howard AD, Kostura MJ, Miller DK, Molineaux SM, Weidner JR, Aunins J, et al: A novel heterodimeric cysteine protease is required for interleukin-1beta processing in monocytes. Nature 356: 768-774, 1992.

38. Miura M, Zhu H, Rotello R, Hartwieg EA and Yuan J: Induction of apoptosis in fibroblasts by IL-1 beta-converting enzyme, a mammalian homolog of the C. elegans cell death gene ced-3. Cell 75: 653-660, 1993

39. Martinon F, Burns K and Tschopp J: The inflammasome: A molecular platform triggering activation of inflammatory caspases and processing of prolL-beta. Mol Cell 10: 417-426, 2002.

40. Bauernfeind F, Ablasser A, Bartok E, Kim S, Schmid-Burgk J, Cavlar T and Hornung V: Inflammasomes: Current understanding and open questions. Cell Mol Life Sci 68: 765-783, 2011

41. Fernandes-Alnemri T, Yu JW, Datta P, Wu J and Alnemri ES: AIM2 activates the inflammasome and cell death in response to cytoplasmic DNA. Nature 458: 509-513, 2009.

42. Hornung V, Ablasser A, Charrel-Dennis M, Bauernfeind F, Horvath G, Caffrey DR, Latz E and Fitzgerald KA: AIM2 recognizes cytosolic dsDNA and forms a caspase-1-activating inflammasome with ASC. Nature 458: 514-518, 2009.

43. Schroder K and Tschopp J: The inflammasomes. Cell 140: 821-832, 2010.

44. Davis BK, Wen H and Ting JP: The inflammasome NLRs in immunity, inflammation, and associated diseases. Annu Rev Immunol 29: 707-735, 2011.

45. Kanneganti TD: Inflammatory bowel disease and the NLRP3 inflammasome. N Engl J Med 377: 694-696, 2017

46. Neudecker V, Haneklaus M, Jensen O, Khailova L, Masterson JC Tye H, Biette K, Jedlicka P, Brodsky KS, Gerich ME, et al: Myeloid-derived miR-223 regulates intestinal inflammation via repression of the NLRP3 inflammasome. J Exp Med 214: 1737-1752, 2017

47. Alijotas-Reig J, Melnychuk T and Gris JM: Regulatory T cells, maternal-foetal immune tolerance and recurrent miscarriage: New therapeutic challenging opportunities. Med Clin (Barc) 144: 265-268, 2015.

48. Saito S, Nakashima A, Myojo-Higuma S and Shiozaki A: The balance between cytotoxic NK cells and regulatory NK cells in human pregnancy. J Reprod Immunol 77: 14-22, 2008.

49. Zhu XY, Zhou YH, Wang MY, Jin LP, Yuan MM and Li DJ: Blockade of CD86 signaling facilitates a Th2 bias at the maternal-fetal interface and expands peripheral CD4+CD25+ regulatory $\mathrm{T}$ cells to rescue abortion-prone fetuses. Biol Reprod 72: 338-345, 2005

50. Harrington LE, Hatton RD, Mangan PR, Turner H, Murphy TL, Murphy KM and Weaver CT: Interleukin 17-producing CD4+ effector $\mathrm{T}$ cells develop via a lineage distinct from the Thelper type 1 and 2 lineages. Nat Immunol 6: 1123-1132, 2005.

51. Park H, Li Z, Yang XO, Chang SH, Nurieva R, Wang YH, Wang Y, Hood L, Zhu Z, Tian Q and Dong C: A distinct lineage of CD4 T cells regulates tissue inflammation by producing interleukin 17 . Nat Immunol 6: 1133-1141, 2005. 